\title{
REAL OR FAKE?
}

Counterfeit, substandard and non-compliant dental devices are a growing problem within the UK dental sector. Increasing online sales and the globalisation of dental manufacturing has created opportunities for unscrupulous operators to introduce poor quality and even illegal products into the marketplace.

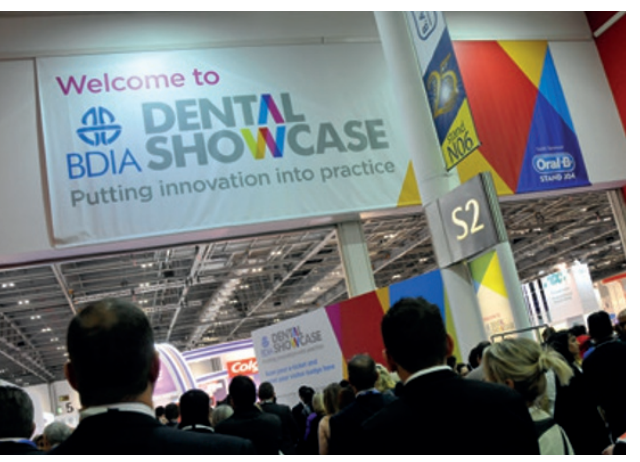

This will be one of the topics of discussion at the upcoming BDIA Dental Showcase at the NEC in Birmingham on 22-24 0ctober. At the show, the British Dental Industry Association (BDIA) will be raising awareness of the issue with its award-winning Counterfeit and Substandard Instruments and Devices Initiative (CSIDI).

Recently featured in an episode of the BBC's 'Fake Britain', the campaign highlights the risks to patients and dental professionals of counterfeit and poor quality products. Through working closely with the Medicines and Healthcare Products Regulatory Agency (MHRA), the British Dental Association (BDA), the British Dental Health Foundation (BDHF), the Tooth Whitening Information Group (TWIG), and other professional bodies across the dental profession, the BDIA encourages the reporting of non-compliant and illegal products and promotes responsible purchasing throughout the dental supply chain.

Visitors can find out more about the CSIDI campaign at the BDIA stand (D145L), where you can also enter the 'Spot the Fake' competition. This challenges you to identify the differences between real and counterfeit instruments and devices. All correct entries will be entered into a draw to win a gift voucher worth $£ 500$ to spend with a BDIA member company of your choice.

To register, check out the full list of exhibitors and the complete Mini and on-stand lecture programme, go to www.dentalshowcase.com.

\section{TAKE THE BITE OUT OF OCCLUSION}

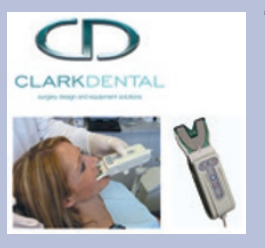

The T-Scan digital occlusal analyser from Clark Dental is one of the most in novative diagnostic products on the market. Unique in its ability to provide an accurate, time-scaled review of a patient's bite force, the T-Scan is improving the way dental professionals diagnose and treat occlusal issues.

\section{At this year's BDIA Den-} tal Showcase, Clark Dental is delighted to present Dr Thomas 0'Connor discussing the revolutionary T-Scan in a number of enlightening lectures. Dr 0’Connor is well-known for speaking on all aspects of aesthetic dentistry and understands the importance of occlusion in achieving top-quality results.

What's more, the eminent Dr Ash Parmar will be taking to the Clark Dental Education Centre on stand G195 to speak about the T-Scan's functional utility in-practice.

With a reputation for bringing dental professionals the best products and equipment on the market, Clark Dental strives to educate as well as equip. For more information contact Clark Dental on 01270613750 orinfo@ clarkdentalsales.co.uk.

\section{EASY HOME-WHITENING}

Most patients are more concerned with the aesthetics of their teeth than their health. Oral-B are excited to introduce their 3D White Whitestrips, which will be exclusively distributed in Europe by Henry Schein. Used as instructed, these are a safe, easy home-whitening treatment, with results that last for up to 12 months. A dental professional first applies the strips, with consumers performing subsequent whitening applications at home. The results are visible within 14 days.

Oral-B's technology marries your patients' concerns for the whiter teeth they desire, whilst dental professionals have the reassurance that with Oral-B's products and their professional guidance, teeth are kept white but also healthy, so everyone is happy!

For further information visit www.dentalcare.co.uk or call 08702421850.

\section{INDEPENDENT FINANCIAL ADVISERS}

The majority of dentists will not be financial experts. The team at money4dentists are.

Running a dental practice as a successful business includes many complicated aspects, some of which are far beyond the knowledge imparted at dental school. To achieve business prosperity and security these factors need to be efficiently managed.

This is where money4dentists can help. With excellent knowledge of the dental sector, the team of expert advisers can help with any financial query practice owners might have. As IFAs, they offer objective, unbiased advice - meaning you can be assured that the only thing they have in mind is your best interests.

Whether it's income protection, mortgage advice or tax planning, the IFAs at money4dentists will provide you with their in-depth knowledge to offer you relevant and appropriate advice, every time.

Contact the friendly and professional team to find out just how they could help you today.

For more information call 08453455060 or visit www.money4dentists.com.

\section{A NEW ADDITION}

Sirona has added pre-shaded translucent zirconium oxide to its wide range of materials for its CAD/CAM systems. inCoris TZI C enables reliable colouring and speeds up the production of aesthetic restorations without veneering.

Fully anatomical restorations can now be made even quicker and with greater colour accuracy. InCoris TZI C is available in ten classic tooth colours and in three different block sizes. The user can save time by using the pre-shaded ceramic blocks, as the restorations no longer need to be dipped and dried in colouring liquid.

For further information call Sirona Dental Systems on 08450715040 or e-mail info@sironadental.co.uk. 